\title{
Details-DNA of Modern Thangka in Re Gong
}

\author{
Qinghua Hu \\ Qinghai Nationlities University, Xining, China \\ Email: h_qh110@163.com
}

How to cite this paper: Hu, Q. H. (2016). Details-DNA of Modern Thangka in Re Gong. Art and Design Review, 4, 119-124. http://dx.doi.org/10.4236/adr.2016.44013

Received: August 6, 2016

Accepted: November 29, 2016

Published: December 2, 2016

Copyright $\odot 2016$ by author and Scientific Research Publishing Inc. This work is licensed under the Creative Commons Attribution International License (CC BY 4.0).

http://creativecommons.org/licenses/by/4.0/

\begin{abstract}
Describing the details is the universality of all artistic forms, but it is painting that treats the details as its artistic features. The Thangka of Re Gong in Qinghai-Tibet Plateau is a typically national and folk art. The reason that it always keeps popular is not only because of the religion reflected by it, but also the typical details description. The delicate sketches embody the excellent techniques, enhance works' resonance and give prominence to theme. This paper aims at analyzing the lines, points, pictures, colors and expressions to draw the outlines of the relatively complete technique chains of DNA.
\end{abstract}

\section{Keywords}

Thangka of Re Gong, DNA, Painting Elements, Details

\section{Introduction}

Thangka of Re Gong, whose core area is the river valley located in Long Wu of Tang Ren county belonging to Huang Nan Tibetan autonomous prefecture in Qinghai province, is an important part of Tibetan Buddhism art. It forms the plastic arts of localism which mix the national cultures of Zang, Tu and Han together after experiencing a long practical history about five or six centuries. With the constant development of social economy and life standard, painting Thangka is changed from a pure religious action to make the Tibetan Buddhism artwares, whose artistic features are also changed from the simple Buddha to depict the overelaborated details. The development of art is confined by society so that the artistic features and evaluation standards keep the active state, which is of obvious uncertainty.

Thangka's perception marks rely on describing stories or primary or secondary Buddhas in Buddhist Texts, which is different from the western religious oil paintings whose law is perspective. "In art, the things treated as contents are actually the forms 
that are used by art to show itself, while what that are treated as forms are artists' expressions power and skills, which constructs the real contents of a artistic work, and the works are evaluated on the basis of this point." Arras, who is a French modern famous art historian and a research scholar studying (Xin He, 2001) Italian literature and art, comes up with the conception of painting details. He wrote down the words, "All the audiences can segment paintings, that is to say, they can split them into different parts. When you appreciate a painting or a picture, you will get the ensemble, but I want to know, at this moment, what do you see on earth? After we have the overall feeling about paintings, our eyes will concentrate on some elements when we are looking at them, and can not only segment the pictures' physical levels, but also seclude something from the ambient vague areas and show something else which is the detail." In his opinion, when seeing the paintings, people can perceive the works on the whole and then observe their details carefully.

Details are finished through delicating the line drawing, and actually this process is a kind of religious behaviour. It takes a long time to finish the excellent Thangka whose complicated pictures, numerous figures and abundant materials need great manpower and material resources. In addition, an obvious detail of drawing Thangka is that it pays more attention to the living situations and survivals' details in secular society, which breaks through the pure belief worships and the models of designs patterns, the regional or segmental reality and the visual expression forms of stories' plots, surpasses the purpose of decorating religious schema, and breaks away from the limitation of measurements, which inject the painting taste into the works.

DNA is short for Deoxyribonudeic acid, which is a carrier of molecule revealing genetic information. Different compositions and arrangements represent different biological functions. Taking long-term information stockpile constitutes genetic details and the gene sequence forms the genetic password. DNA is a medical conception, which is widely used in the fields of genetic engineering, medicolegal expertise, history and anthropology because of its special physical and chemical functions. Here, the DNA of Thangka mainly refers to that the arrangements of its artistic symbols and the internal regulars of artistic features, which have coding, copying and transcribing functions kept by DNA. Like all the religious arts, both Thangka and the western Christian paintings express the worship for the religion and their drawings are rarely smeared or messy. As a typical example of detailed paintings, when we analyze Thangka, we need find its internal regulars and the common code of different schools.

\section{From Old Thangka to Modern Thangka}

The old Thangka mainly are the works of Ming and Qing dynasties. Because of the low level of production, its pictures, lines, colors and decorations are restricted by the technique. The big Thangka are always painted on several hand tailoring cotton clothes. The artistic features of old Thangka in Re Gong are composed the depth of religious connotation, aesthetic breadth and the flexible technique of using dark colors. Due to efflorescence and time, the pigment of early Thangka cannot be identified between 
green and blue, which is like mottled bronze and is eternally renewed. As time goes on, the religious function of the old Thangka has been replaced by its own cultural values. The old Thangka becomes invaluable for collectors because of purely handmade and natural mineral materials and the old gulch-gold craftsmanship and it is of non-renewable value.

The early Thangka whose purpose is homiletic is simple and dignified, which is different from exquisite sculpture of the modern Thangka whose purpose is decoration. However, the difference does not mean disparity and the distance of space does not change its religious and artistic heredity venation. "We are not sure which one is of higher level. They have their own characteristics that cannot be replaced by the other one. The changeable process only represents time and does not mean artistic achievements." People who making the old Thangka can express their piety for Buddha and Bodhisattva (Geming Zhang, 2010) and the attitude towards life in the relatively fixed pattern, and now these makers also try their best to integrate what they have learned into the philosophy of Tibetan Buddhism and the ideality of life. Both the old Thangka and the modern one have complex and well-organized content, abundant and ordered hiberarchy, bright and vivid color and proper material percentage.

\section{Details of Painting Elements}

The detail is not only the most typical feature of Thangka in Re Gong, but also runs through the whole Thangka's painting process. We can analyze its detail genes of technique chains through the basic drawing units.

Line is the clearest element of genetic passwords in old Thangka, and the use of line is the quintessence of Thangka art. Though the line in the old Thangka is simple and relatively stable, we can find the capability is unwillingly deep and the works are finished from beginning to end without stopping. The brushwork is coherent and does not have any modification. The artists attach importance to studying drawing the lines from generation to generation, and treat this as the basis of studying and inheriting Thangka technique. If an apprentice does not master this skill, he will not allowed to enter the next stage. Now the artists in Re Gong realize the line's decisive function in the more outstanding works more profoundly when they inheriting the old feature, who think dealing with the interval and density among the lines can show the drawing techniques.

The value of lines in Thangka relies on moire, watermark and fire grain. The Buddhas, figures and environments are described as vivid as real ones. The tranquil pictures look very dynamic, which presents infinite vitality. It is worth keeping a watching eye on how the lines look like the surface. The artists use a lot of thick lines to form the surface and many transitional areas. The beauty of some lines can only be appreciated through the magnifying lens and the typical example is the join between the sky and ground, which is exquisite and fluent and like a natural formation. It is drawing the decorative lines directly without drafts on the bottom color covered with gold that can embody the artists' line techniques. The perfectly accurate lines appear in many works 
of Jin Tang, Hei Tang and Hong Tang, which is the acclaim as the peak of perfection. In a series of medical Thangkas of the traditional Tibetan medicine, the fine and silky lines can not only reveal people's neuroses, blood vessels and venations, but also their anteroposterior position, even though the high-definition digital technology cannot be of this function.

The point is the smallest unit, which is the basis of relationship between line and surface, it is also the most suitable skill for detail expressions. In Thangka, the different sizes and densities of points make the designs have multiple changes, and they are also the decorative methods of abstract shape. Thangka of Re Gong uses the points not just for describing images. When the drawing begins, the points' function come into play. The positions of the central point, right-and left symmetrical point and the elliptical and apheliotropic center of a circle all need to be confirmed, which have great influences on the color transition, abundant body shape and decorative effect.

Drawing symmetrically is the keynote of Thangka. In the early time the works of Tibetan Buddhism made the most of beauty formed by symmetry and balance. The main Buddha of Thangka is always on the axle wire of the picture, which forms a close unity. Wen Shu Bai Zun, enshrined in the art gallery of Re Gong which is in Huang Nan Tibetan autonomous prefecture of Qinghai province, is a masterpiece of Ming and Qing Dynasty. Its length is $90 \mathrm{~cm}$ and the width is $70 \mathrm{~cm}$. Up to now the painter is unknown. In this small work there are almost 240 Bodhisattvas, which shows that the workmanship is very delicate.

The detail permeates the artists' color idea in Re Gong. With the quiet change of Thangka's style, the fact that color serves for decoration becomes more and more distinct. The peculiarity is that the thick color turns weak gradually and changes from deep to shallow. This is not realized through color modulation, in fact because during the long drawing process, the artists unconsciously lick the paintbrushes to make the works moist and dilute the pigments' saturability, and in the end this effect is formed. The transition is natural and fluent. Through some pigments are toxic, this gradation effect cannot be found in other paintings. Using the pure gold to draw is another feature of Thangka. The gold can be used for body shape and the bottoms. The platinum and gold are differentiated very clearly, which makes the immortal world more gorgeous.

The detail of Buddhas' expressions is a critical part in Thangka's technique chain. Buddhas' images and expressions integrate the truth, the goodness and the beauty, which is the most tender content touching people's hearts. The detail depiction of eyes, mouths and noses is the key element of spiritual characteristics. The first step of drawing eyes always is finished by the old artist with abundant experience and the mediocre painters dare not to begin their works hastily. This is a key point including delineation of outlines and shade of colors, which decides whether the work is successful. "Opening The Eyes covers drawing eyes, mouths, noses, hands, feet and nails and so on. The artists must know the eyes' differences of the Apsara, the Buddha, the Bodhisattva and the ordinary people in diverse situations such as walking, sitting, sleeping and so on." The 
color of eyeballs is very light, which looks like mist. Then the pupils can be accomplished. When the artists render the eyelids, the color of the Buddhas and the Bodhisattvas is blue; the Fen Nu Buddhas need vermilion or the color which is similiar to the yellow lead. As to the beautiful women, for example Sarasvati, they need auratus. However, actually during the drawing process, the artists can use flaxen, indigo or other colors. In terms of the benefactors' economic conditions, sometimes they can use gold juice to tint the eyeballs and eyelids of Jing Meng Buddhas." Through the long-term inheritance and competitions of drawing technique, the artists (Gengsheng Bai, 2007) surpass and break through the old patterns. Though the measurement proportion is very rigorous, different artists paint different Buddhas.

\section{Foreignization and Domestication}

The detail description is not like the realism paintings which mainly imitate photos. These detail images have been given to patterns by measurement in the early time. However, these patterns are not stationary and because of the artists' different purposes and needs, they will be also changed. "The most direct reason that makes the tourists moved and wants to buy these artwares is themselves. In modern art, the reception theory and aesthetic psychology think if the artistic activities want to be accepted, at first the material media must need to be accepted, it is the most intuitive and exterior tier of an artistic works. That is to say, the artists' color, line, light and shade, and shape must be accepted." (Yan Li, 2009) The peculiarity of decoration stimulates the artists to improve their line drawing techniques constantly. The feature of detail description is also enhanced on the basis of the traditional style, which becomes the core content of competitions between the artists' families and the communities.

"On the foundation of overall inheritance, it is emphasized that painting should give play to the traditional advantages of techniques and specialties, so that it can make perfection more perfect. At the same time, the artists can use some new forms to enrich the aesthetic taste of paintings. As to the craft, it should keep the original state and does not make the stylistic foreignization come into being." (Gesangyixi Kang, 2005) The combination of many details forms the coincident mental images of the appreciators and pictures, which shows the deep religious idea and emotions that are beyond expressions and deducts the mysterious superpower. The strong and visual feel is of the great power that can push the religious belief forward.

All the details witness the artists' great endeavor and care and give expression to Thangkas' artistic features which is similar to DNA, which makes the works not rigid but solemn, not vulgar but showy. Even so, expressing and deepening the details are still the original part for the Re Gong's artists in the new period. Finding and creating the details are still going on. Actually in the old Thangka, the artists make great efforts to realism for the pure religion and in the modern artworks, the main purpose is decoration. However, both of them have a common code that is observing, understanding and expressing the details. No matter how the artistic style changes, the detail is a genic element which cannot be shifted, and it becomes the real DNA of Thangka in Re Gong. 


\section{References}

Bai, G. S. (2007). Chinese Thangka Art Integration (Wu Tun Volume). Yinchuan: Ningxia People's Press, 50-52.

He, X. (2001). Art Analysis and Aesthetic Speculation. Beijing: Current Affairs Press, 50-51.

Kang, G. (2005). The History of Tibetan Art. Chengdu: Sichuan Publishing Group, 455-457.

Li, Y. (2009). Recurrence and Reconstruction: The Moment of Traditional Folk Arts. Kunming: Yunnan University Press, 250-253.

Zhang, G. M. (2010). The Creators of Heavy on Describing. Shenyang: Liaoning Arts Press, 65-67.

Submit or recommend next manuscript to SCIRP and we will provide best service for you:

Accepting pre-submission inquiries through Email, Facebook, LinkedIn, Twitter, etc. A wide selection of journals (inclusive of 9 subjects, more than 200 journals)

Providing 24-hour high-quality service

User-friendly online submission system

Fair and swift peer-review system

Efficient typesetting and proofreading procedure

Display of the result of downloads and visits, as well as the number of cited articles Maximum dissemination of your research work

Submit your manuscript at: http://papersubmission.scirp.org/

Or contact adr@scirp.org 